Seminar Nasional Teknologi Informasi dan Kedirgantaraan (SENATIK)

Vol. III, 21 Desember 2017, P-ISSN: 2337-3881, E-ISSN: 2528-1666

DOI: http://dx.doi.org/10.28989/senatik.v3i0.110

\title{
SELEKSI TANAMAN UMBI-UMBIAN \\ BERDASAR ZAT KIMIA LAHAN MENGGUNAKAN ALGORITMA GENETIK (STUDI KASUS:DI KABUPATEN BANTUL)
}

\author{
Yuliani Indrianingsih \\ Departemen Informatika \\ Sekolah Tinggi Teknologi Adisutjipto \\ Jln. Janti Blok R Lanud Adisutjipto Yogyakarta \\ Email : yulistta@gmail.com
}

\begin{abstract}
This study aims to improve the economic value of farmers' land in the district of Bantul, so that the land has a higher economic value with the appropriate plants. Many farmers are still using self-learning and experience from generation to generation in determining the pattern of plant species, so that the harvest not optimal. So we need a system that can help farmers to determine the type of tuber plants suitable for chemical substances land. The research was conducted in Bantul District for data collection in the field. The results of data collection in the field can be a benchmark for the decision of farmers to determine the type of tuber plants to be planted based on the criteria of soil nutrition. Criteria is a barometer determining the type of tuber is KTK, $O$, Ca, C / N, Magnesium, Carbon. This research uses genetic algorithm. The results showed that the best tuber plant rank in Bantul Regency was the first rank of red onion, followed by garut bulbs, sweet potato and root talas. Genetic algorithm can be applied for tuber selection in Bantul regency, but has a weakness because it is probabilistic.
\end{abstract}

Keywords : Selection, tubers, genetic algorithm

1. Pendahuluan

Ketahanan pangan Indonesia tergolong rawan mengingat areal yang diperuntukkan tanaman pangan sangat terbatas. Oleh karenanya, pemerintah harus mengambil langkah-langlah strategis guna mewujudkan ketahanan pangan.

Salah satunya adalah penentuan jenis tanaman umbi-umbian berdasarkan kandungan zat kimia lahan. Tanaman umbiumbian merupakan tanaman kedua, setelah padi, meliputi ubi ketela pohon, ubi jalar, ubi garut, ubi talas, ubi kimpul. Sedangkan umbi dapat digolongkan menjadi 3 golongan yaitu umbi akar, umbi lapis, dan umbi batang. Tanaman ini mempunyai nilai ekonomis selain tanaman padi yang banyak ditanam petani. Penentuan jenis tanaman umbi-umbian ini akan sangat bermanfaat bagi masyarakat umum khususnya yang berprofesi sebagai petani, karena dengan adanya sistem ini, maka petani dapat menentukan jenis tanaman umbi-umbian yang cocok untuk ditanam dilahan mereka.
Kabupaten Bantul Propinsi DIY mempunyai sebanyak 17 Kecamatan yang tersebar, ibukotanya adalah Bantul. Moto Kabupaten ini adalah Projotamansari singkatan dari Produktif-Profesional, Ijo royo royo, Tertib, Aman, Sehat, dan Asri. Kabupaten ini berbatasan dengan Kota Yogyakarta dan Kabupaten Sleman di utara, Kabupaten Gunung Kidul di timur, Samudra Hindia di selatan, serta Kabupaten Kulon

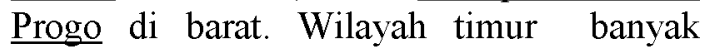
dijumpai lahan kering diantara perbukitan.

Beriklim tropis dengan cuaca panas sebagai ciri khasnya. Berdasarkan data dari Dinas Kependudukan Kabupaten Bantul luas daerah di Kabupaten Bantul adalah $50.6785 \mathrm{Ha}$ dan sebagian besar penduduknya adalah petani.

Usaha-usaha konservasi yang selama ini dilakukan di sebagian wilayah Kabupaten Bantul antara lain dengan menanam tanaman tahunan, tanaman makanan ternak, tanaman umbi-umbian, tanaman jagung yang banyak dijumpai di lahan tersebut. Tindakan yang lain melakukan perbaikan 
agar lahan dapat kembali menjadi produktif. Sistem konservasi memang cocok untuk lahan yang kering, tetapi untuk pergiliran tanaman apa yang cocok untuk lahan tersebut masih bersifat turun temurun atau hal yang biasa dilakukan. Untuk mengurangi resiko kegagalan di lahan kering, sangat dianjurkan melakukan pola aneka usaha tani secara terpadu.

Berdasarkan hal tersebut di atas, akan dibuat sistem untuk seleksi jenis tanaman umbi-umbian pada lahan kering pertanian. Penentuan jenis tanaman ini akan sangat bermanfaat bagi masyarakat petani, karena dengan adanya sistem ini petani dapat menentukan jenis tanaman yang cocok untuk ditanam di lahan kering pertanian sehingga dapat memperbaiki kesejahteraan petani.

\section{Landasan Teori}

Algoritma genetika berangkat dari himpunan solusi yang dihasilkan secara acak yang disebut populasi. Sedangkan setiap individu dalam populasi disebut kromosom yang merupakan representasi dari solusi dan masing-masing dievaluasi tingkat ketanggguhannya (fitness) oleh fungsi yang telah ditentukan. Melalui proses seleksi alam atas operator genetik, gen-gen dari dua kromosom (disebut parent) diharapkan akan menghasilkan kromosom baru dengan tingkat fitness yang lebih tinggi sebagai generasi baru atau keturunan (offspring) berikutnya. Kromosom-kromosom tersebut akan mengalami iterasi yang disebut generasi (generation). Pada setiap generasi, kromosom dievaluasi berdasarkan nilai fungsi fitness (Gen dan Cheng, 2000). Setelah beberapa generasi maka algoritma genetika akan konvergen dapat kromosom terbaik, yang merupakan solusi optimal (Goldberg, 1989).

Individu yang lebih kuat akan memiliki tingkat survival dan tingkat reproduksi yang lebih tinggi jika dibandingkan dengan individu yang kurang fit. Pada kurun waktu tertentu (sering dikenal istilah generasi), populasi secara keseluruhan akan lebih banyak memuat organisme yang fit.

Algortima genetika berbeda dengan teknik pencarian konvensional, dimana dimulai dengan suatu inisial solusi acak yang disebut populasi. Masing-masing individu di dalam populasi disebut kromosom. Kromosom adalah simbol-simbol string biasanya binary string. Solusi dari satu populasi diambil dan digunakan untuk membentuk populasi baru. Ini dimotivasi oleh harapan, dimana populasi baru akan lebih baik dari populasi yang lama. Solusi yang terpilih untuk membentuk keturunan baru (offspring) berdasarkan nilai fitnessnya. Semakin baik nilainya, maka semakin besar pula kesempatannya untuk diproduksi.

\subsection{Metode Seleksi}

Seleksi bertujuan untuk memberikan kesempatan reproduksi yang lebih besar lagi kepada anggota populasi yang paling fit. Langkah pertama seleksi adalah mencari nilai fitness. Masing-masing individu dalam satu wadah seleksi akan menerima probabilitas reproduksi yang tergantung dari nilai objektif dirinya sendiri terhadap nilai objektif dari semua individu dalam wadah seleksi tersebut. Nilai fitness inilah yang nantinya akan digunakan pada tahap seleksi bertikutnya.

Ada beberapa macam metode seleksi, antara lain sebagai berikut :

1. Rank-based fitness assignment Seleksi rangking terlebih dulu merangking atau mengurutkan kromosom di dalam populasi berdasarkan fitnessnya kemudian memberi nilai fitness baru bernilai 1 , terburuk kedua bernilai 2 dan seterusnya, sehingga kromosom yang memiliki fitness terbaik akan memiliki fitnessnya $\mathrm{N}$, dimana $\mathrm{N}$ adalah jumlah kromosom di dalam populasi.

2. Roulette wheel selection

Pada metode Roulette wheel selection, parent dipilih berdasarkan nilai fitnessnya, semakin baik nilai fitnessnya maka semakin besar kemungkinannya untuk terpilih.

3. Stochastic universal sampling

Stochastic universal sampling memiliki nilai bias nol dan penyebaran yang minimum. Pada metode ini, individu-individu dipetakan dalam suatu segmen garis secara berurutan hingga tiap-tiap segmen individu memiliki ukuran yang sama dengan ukuran fitnessnya 
seperti halnya pada seleksi roda roulette, dan diberikan sejumlah pointer sebanyak individu yang diseleksi di garis tersebut. Andaikan $\mathrm{N}$ adalah jumlah individu, dan posisi pointer pertama diberikan secara acak pada range $[1,1 / \mathrm{N}]$.

4. Local selection (seleksi lokal)

Pada seleksi lokal setiap individu yang berada di dalam constraint tertentu disebut dengan nama lingkungan lokal. Interaksi antarindividu hanya dilakukan dalam wilayah tersebut.

5. Truncation selection (seleksi pemotongan)

Truncation selection memilih peringkat dari semua individu menurut fitness dan memilih seleksi terbaik sebagai orang tua.

6. Tournament selection

Pada metode seleksi dengan turnamen ini, akan ditetapkan suatu nilai tour untuk individu yang dipilih secara random dari suatu populasi. Individu yang terbaik dalam kelompok ini akan diseleksi sebagai induk.

\subsection{Crossover}

Crossover (penyilangan) adalah operator algoritma genetika yang membutuhkan parameter dua kromosom induk untuk menghasilkan kromosom anak (offspring) yang akan mewarisi sebagian sifat kromosom induknya. Contoh crossover

Parent 1

$$
\begin{array}{llllllll}
1 & 0 & 1 & 0 & 0 & 1 & 1 & 0
\end{array}
$$

Parent 2

$$
\begin{array}{llllllll}
0 & 1 & 0 & 1 & 0 & 1 & 0 & 0
\end{array}
$$

yang posisi titik potongnya dipilih secara acak adalah 3, maka diperoleh :

Offspring 1

$\begin{array}{lllllllll}\text { Offspring } 2 & 0 & 1 & 0 & 0 & 0 & 1 & 1 & 0\end{array}$

Pada crossover ada satu parameter yang sangat penting yaitu peluang crossover $(P c)$ dengan nilai adalah 0,25 . Peluang crossover menunjukkan rasio dari anak yang dihasilkan dalam setiap generasi dengan ukuran populasi.

\subsection{Mutasi}

Pada dasarnya mutasi akan mengubah secara acak nilai suatu bit pada posisi tertentu, dimana bit 1 digantikan dengan 0 atau sebaliknya. Pada mutasi ini sangat dimungkinkan munculnya kromosom baru yang semula belum muncul dalam populasi awal. Contoh mutasi :

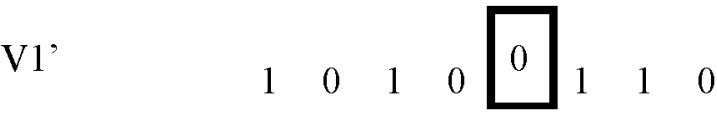
yang terkena mutasi pada gen ke-5, maka diperoleh :

$\mathrm{V} 1^{*}$

$$
\begin{array}{lllllllll}
1 & 0 & 1 & 0 & 1 & 1 & 0
\end{array}
$$

Pada mutasi ada satu parameter yang sangat penting yaitu peluang crossover ( $\mathrm{Pm}$ ) dengan nilai adalah 0,01 . Peluang mutasi menunjukkan prosentasi jumlah total gen pada populasi yang akan mengalami mutasi. Beberapa hal yang termasuk kelebihan dari Algoritma Genetika adalah sebagai berikut :

a. Mengoptimalkan dengan variabel kontinu atau diskrit,

b. Tidak memerlukan informasi derivatif,

c. Bersamaan pencarian dari sebuah sampling yang luas pada permukaan biaya,

d. Berkaitan dengan sejumlah besar variabel,

e. Memberikan daftar variabel yang optimal, bukan hanya solusi tunggal,

f. Dapat menyandikan variabel sehingga optimasi dilakukan dengan mengkodekan variabel, dan

g. Bekerja dengan data numerik yang dihasilkan, data eksperimen, atau analitis fungsi.

Umbi terbagi menjadi beberapa kelompok menurut asal terjadinya yaitu umbi akar, umbi batang, dan umbi lapis. Umbi akar contohnya adalah tanaman ketela pohon atau singkong, wortel, uwi, ubi jalar. Umbi batang contohnya adalah tanaman talas, suweg, kentang. Sedangkan contoh umbi lapis adalah bawang merah dan bawang bombay.

Berdasarkan asal terbentuknya tanaman umbi-umbian terbagi menjadi tiga kelompok yaitu :

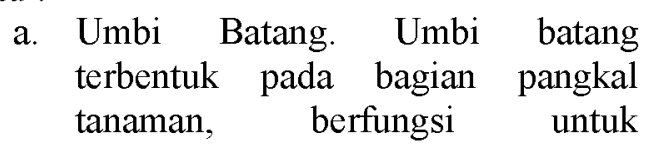


menyimpan cadangan makanan bagi tanaman tersebut. Contoh umbi batang yaitu tanaman kentang, tanaman talas dan tanaman sente.

b. Umbi Akar. Umbi akar terbentuk karena perkembangan akar yang membesar, karena penumpukan nutrisi dalam waktu tertentu untuk cadangan makanan pada tanaman terebut. Contoh umbi akar yaitu tanaman singkong, tanaman kimpul, tanaman garut, tanaman wortel dan tanaman ubi jalar.

c. Umbi Lapis. Umbi lapis salah satu umbi yang berlapuis-lapis. Umbi ini biasanya ujungnya bersatu dengan daun dan pangkalnya dengan akar. Contoh umbi lapis yaitu tanaman bawang merah dan bawang bombay.

\section{Metode Penelitian}

Penelitian dilakukan dengan observasi langsung di wilayah 5 (lima) Kecamatan di Kabupaten Bantul, serta melakukan wawancara dengan Petugas BP3K Pertanian Kecamatan, yaitu proses komunikasi dan pengisian data tanaman. Pemilihaan lokasi berdasar letak geografisnya, dengan struktur tanah yang berbeda. Dalam proses perhitungan ada beberapa kriteria tanaman yang akan digunakan, yaitu :

1. Kapasitas Tukar Kation (KTK)

2. Kejenuhan basa (KB)

3. $\mathrm{PH} \mathrm{H}_{2} \mathrm{O}$

4. $\mathrm{C} / \mathrm{N}$

5. Fosfor $(\mathrm{P})$

6. Kalium $(\mathrm{K})$

7. Natrium $(\mathrm{Na})$

8. Kalsium (Ca)

9. Magnesium $(\mathrm{Mg})$

10. Carbon (C)

Dengan rating kecocokan pada setiap kriteria, dinilai dengan angka $1-5$, dimana setiap angka memiliki predikat tersendiri yaitu :
1. $\quad$ Sangat Kurang $=1$.
2. Kurang $=2$.
3. $\quad$ Cukup $=3$.
4. $\quad$ Baik $=4$
5. $\quad$ Sangat Baik $=5$.

Dari setiap penilaian yang telah dilakukan oleh Petugas BP3K Pertanian akan mengisi kriteria seperti di atas. Untuk langkah- langkah pembuatan sistem dibuat tahapan penelitian menggunakan flowchart sebagai berikut :

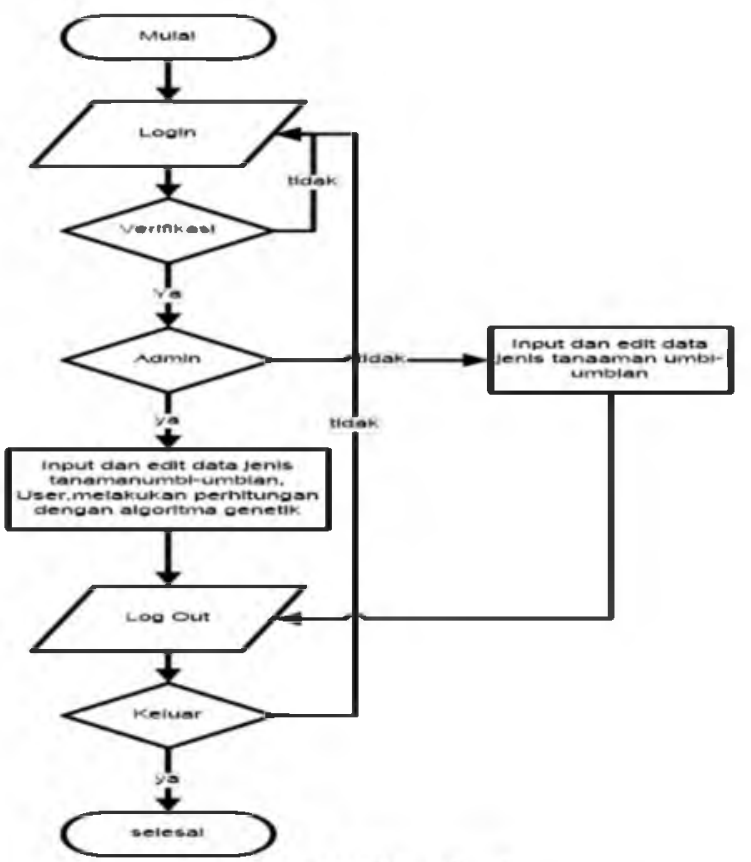

Gambar 1 Flowchart

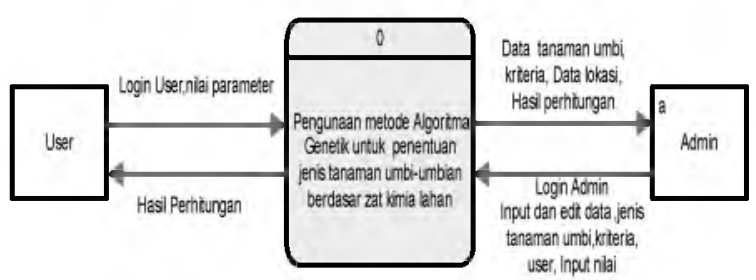

Gambar 2 Diagram

konteks

User melakukan login, dalam hal ini Petugas BP3K Kecamatan dapat mendaftar untuk menjadi user baru, melakukan input dan edit data. Sistem yang dibangun menggunakan algoritma genetik, tahap yang dilakukan adalah sebagai berikut :

1. Representasi (penyandian) kromosom. Teknik penyandian meliputi penyandian gen dari kromosom. Gen merupakan bagian dari kromosom. Satu gen biasanya akan mewakili satu variabel. Setiap gen merepresentasikan tanaman, dimana setiap tanaman mempunyai nilai yang merupakan jumlah total setiap kriteria tanaman yang dikalikan dengan bobot dari setiap kriteria. Bentuk representasi tanaman dapat dilihat pada Tabel 1. 
Tabel 1 Representasi kromosom

\begin{tabular}{|l|c|c|c|c|c|}
\hline Kriteria & Bobot & $\begin{array}{c}\text { Tnm } \\
01\end{array}$ & $\begin{array}{c}\text { Tnm } \\
02\end{array}$ & $\begin{array}{c}\text { Tnm } \\
03\end{array}$ & $\begin{array}{c}\text { Tnm } \\
04\end{array}$ \\
\hline KTK & 3 & 2 & 2 & 3 & 2 \\
\hline $\begin{array}{l}\text { Kejenuh } \\
\text { an Basa }\end{array}$ & 4 & 4 & 1 & 1 & 5 \\
\hline PH H2O & 2 & 2 & 1 & 2 & 2 \\
\hline C/N & 3 & 2 & 2 & 1 & 2 \\
\hline Posfor & 1 & 1 & 1 & 1 & 1 \\
\hline Kalium & 5 & 4 & 2 & 1 & 3 \\
\hline Natrium & 1 & 1 & 1 & 1 & 1 \\
\hline Kalsium & 3 & 3 & 1 & 1 & 2 \\
\hline $\begin{array}{l}\text { Magnesi } \\
\text { um }\end{array}$ & 2 & 2 & 1 & 1 & 2 \\
\hline Carbon & 5 & 1 & 1 & 5 & 1 \\
\hline
\end{tabular}

Dimana kode kromosom merupakan jenis tanaman umbi-umbian, yaitu jenis:
Tanaman $01=$ Bawang merah
Tanaman $02=$ Ubi jalar
Tanaman $03=$ Talas
Tanaman $04=$ Garut.

Rumus menghitung bobot dari masingmasing tanaman adalah sebagai berikut:

Dimana :

$$
\text { Nilai }=\sum(\mathrm{Bi} * \mathrm{Ki})
$$

$\mathrm{Bi}=$ Bobot kriteria ke-i

$\mathrm{Ki}=$ Kriteria ke $-\mathrm{i}$

Perhitungan nilai untuk tanaman 01 , tanaman 02, tanaman 03 dan tanaman 04 untuk data dan bobotnya,yaitu:

Nilai Tanaman $01=$

$(6+16+4+6+1+20+1+9+4+5)$

Nilai Tanaman $01=72$

Tahap kedua yaitu membangkitkan populasi awal dan menghitung nilai fitness Inisialisasi populasi awal dilakukan secara random sebanyak yang diinginkan dengan cara membangkitkan bilangan random dari 1 (satu) sampai jumlah kromosom/populasi pada setiap gen. Pada suatu proses dihasilkan populasi awal dengan jumlah populasi adalah 10 , jenis tanaman 01 s.d 04 merupakan urutan kromosom 1 s.d 4 . Pengevaluasian setiap kromosom didapat dari rata-rata jumlah total nilai semua tanaman yang dikalikan dengan bobotnya. Apabila ditulis dalam model matematis, maka hasilnya adalah :

Fitness $=\frac{\mathbf{n} * \text { Nilai }_{\mathbf{n}}+(\mathbf{n}-\mathbf{1}) * \text { Nilai }_{\mathbf{1}}+\cdots+\text { Nilai }_{\mathbf{n}-\mathbf{1}}}{\mathbf{n}}$

Dimana :

Nilai $_{n}$

ke-0 (72)

Nilai $_{1}$

ke-1 (40)
Nilai $_{2} \quad=$ Nilai tanaman pada gen

ke-2 (57)

Nilai $_{n-1} \quad=$ Nilai tanaman pada gen

terakhir )

$\mathrm{n} \quad=$ Jumlah gen (4)

Untuk perhitungan nilai fitness populasi ke-1

yaitu :

Fitness

$=\frac{((4 * 57)+((4-1) * 72)+((4-2) * 40)+((4-3) * 68))}{4}$

Fitness

$$
\begin{aligned}
& =\frac{((4 * 57)+(3 * 72)+(2 * 40)+(1 * 68))}{4} \\
& \text { Fitness }=\frac{((228)+(216)+(80)+(68))}{4} \\
& \text { Fitness }=\frac{(592)}{4}
\end{aligned}
$$

Fitness $=148$

Tabel 2 Populasi awal

\begin{tabular}{|c|c|c|c|c|c|}
\hline Populasi Ke- & \multicolumn{3}{|c|}{ Kromosom } & Fitness \\
\hline Populasi Ke -0 & 3 & 1 & 2 & 4 & 148 \\
\hline Populasi Ke -1 & 1 & 4 & 2 & 3 & 157,25 \\
\hline Populasi Ke -2 & 4 & 3 & 2 & 1 & 148,75 \\
\hline Populasi Ke -3 & 2 & 4 & 3 & 1 & 137,5 \\
\hline Populasi Ke -4 & 4 & 3 & 1 & 2 & 156,75 \\
\hline Populasi Ke -5 & 4 & 3 & 1 & 2 & 156,75 \\
\hline Populasi Ke -6 & 2 & 4 & 1 & 3 & 141,25 \\
\hline Populasi Ke -7 & 4 & 3 & 2 & 1 & 148,75 \\
\hline Populasi Ke -8 & 1 & 2 & 4 & 3 & 150,25 \\
\hline Populasi Ke -9 & 2 & 4 & 3 & 1 & 137,50 \\
\hline
\end{tabular}

Tahap ketiga yaitu seleksi setelah proses inisialisasi dan fitness dilakukan, maka langkah berikutnya adalah proses seleksi. Untuk proses seleksi digunakan metode seleksi Roda Roulette (Roulette Selection). Sebelum proses seleksi dilakukan maka terlebih dahulu dihitung probabilitas fitness dan komulatif probabilitas fitness masingmasing kromosom.

Untuk perhitungan probabilitas fitness dengan masing-masing kromosom adalah :

$$
P_{k}=\frac{F_{k}}{\text { TotFitness }}
$$

Untuk perhitungan komulatif probabilitas fitness dengan masing-masing kromosom adalah :

$$
\begin{gathered}
q_{1}=p_{1} \\
q_{k}=q_{k-1}+p_{k}
\end{gathered}
$$

Untuk nilai komulatif probabilitas fitness populasi ke-1, berdasarkan rumus $q_{1}=p_{1}$, maka :

Komulatif probabilitas fitness populasi ke-1 $=0,0998$.

Tabel 3 Komulatif Probabilitas 


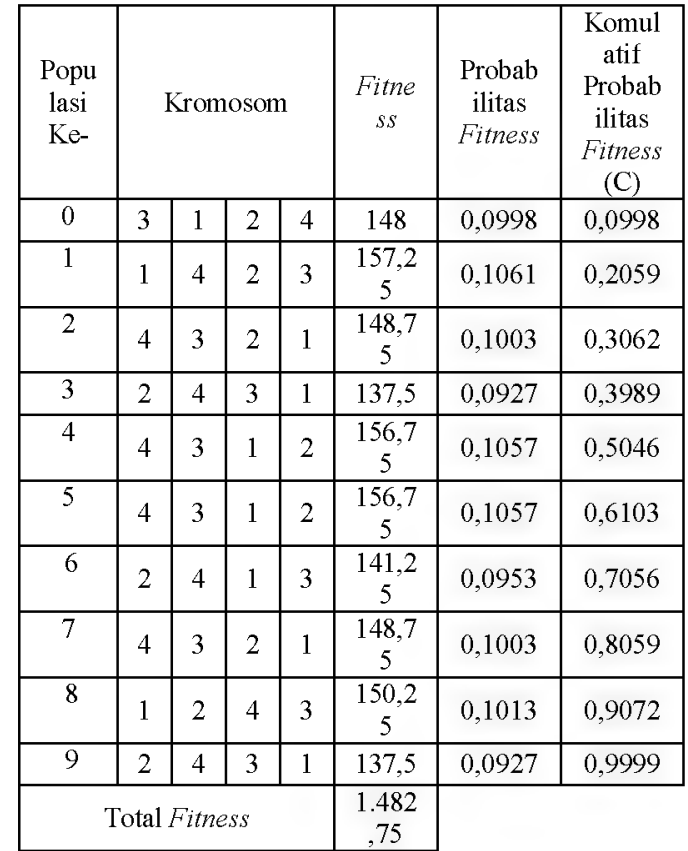

Dari perhitungan probabilitas yang sudah dibuat maka dapat dilihat bahwa populasi ke - 1 yang mempunyai fitness paling besar, dengan begitu populasi tersebut mempunyai probabilitas untuk terpilih pada generasi berikutnya lebih besar dibandingkan dengan populasi yang lainnya.

Setelah dilakukan proses penghitungan komulatif probabilitas fitness, maka proses seleksi dilakukan dengan menggunakan roulette-wheel sebanyak jumlah populasi, yaitu 10 kali dengan cara membangkitkan bilangan acak (random) dalam range $0-1$. Jika random $[\mathrm{k}]<\mathrm{C}[\mathrm{k}]$, maka pilih populasi sebagai induk, selain itu pilih populasi ke-k sebagai induk dengan syarat $\mathrm{C}[\mathrm{k}-1]<$ Random $<\mathrm{C}[\mathrm{k}]$.

Setelah dilakukan proses random maka diperoleh populasi baru seperti pada Tabel 4 . Tabel 4 Tabel populasi baru hasil seleksi

\begin{tabular}{|c|c|c|c|c|c|}
\hline Populasi Awal & $\begin{array}{c}\text { Populasi } \\
\text { Baru }\end{array}$ & \multicolumn{5}{|c|}{ Kromosom } \\
\hline Populasi [0] & Populasi [7] & 4 & 3 & 2 & 1 \\
\hline Populasi [1] & Populasi [3] & 2 & 4 & 3 & 1 \\
\hline Populasi [2] & Populasi [5] & 4 & 3 & 1 & 2 \\
\hline Populasi [3] & Populasi [5] & 4 & 3 & 1 & 2 \\
\hline Populasi [4] & Populasi [8] & 1 & 2 & 4 & 3 \\
\hline Populasi [5] & Populasi [1] & 1 & 4 & 2 & 3 \\
\hline Populasi [6] & Populasi [9] & 2 & 4 & 3 & 1 \\
\hline Populasi [7] & Populasi [3] & 2 & 4 & 3 & 1 \\
\hline Populasi [8] & Populasi [7] & 4 & 3 & 2 & 1 \\
\hline Populasi [9] & Populasi [7] & 4 & 3 & 2 & 1 \\
\hline
\end{tabular}

2. Perkawinan Silang (Crossover). Pada proses perkawinan silang (crossover) digunakan metode one-cut point atau memilih secara acak satu posisi dalam populasi induk kemudian saling menukar kromosom. Populasi yang akan dijadikan induk dipilih secara random, dimana jumlah populasi yang mengalami crossover dipengaruhi oleh parameter crossover rate $(\mathrm{pc})$. Jika nilai random $[\mathrm{k}]<$ pc maka, populasi tersebut terpilih jadi induk. Pada kasus ini, jumlah induk ada 4 (empat) yaitu : populasi ke - 4 dengan nilai random 0,1845 , populasi ke -4 dengan nilai random 0,2303 , populasi ke -6 dengan nilai random 0,137 dan populasi $\mathrm{ke}-7$ dengan nilai random 0,1818 .

Setelah menentukan populasi yang akan mengalami crossover, maka selanjutnya dilakukan langkah untuk menentukan titik potong crossover yaitu dengan membangkitkan bilangan random dari 1 (satu) sampai panjang induk crossover atau pada kasus ini dari $1-4$ (didapat titik potongnya pada populasi ke -3). Maka diperoleh hasil crossover seperti pada Tabel 5.

Tabel 5 Tabel Crossover

\begin{tabular}{|c|c|c|c|c|c|c|c|c|c|c|c|}
\hline $\begin{array}{c}\text { Popula } \\
\text { si }\end{array}$ & \multicolumn{4}{|c|}{ Kromosom } & & \multicolumn{2}{|c|}{$\begin{array}{c}\text { Popula } \\
\text { si }\end{array}$} & \multicolumn{3}{|c|}{ Kromosom } \\
\hline $\begin{array}{c}\text { Popula } \\
\text { si [4] }\end{array}$ & 1 & 2 & 4 & 3 & X & $\begin{array}{c}\text { Popula } \\
\text { si [7] }\end{array}$ & 2 & 4 & 3 & 1 \\
\hline $\begin{array}{c}\text { Popula } \\
\text { si [5] }\end{array}$ & 1 & 4 & 2 & 3 & X & $\begin{array}{c}\text { Popula } \\
\text { si [4] }\end{array}$ & 1 & 2 & 4 & 3 \\
\hline $\begin{array}{c}\text { Popula } \\
\text { si [6] }\end{array}$ & 2 & 4 & 3 & 1 & X & $\begin{array}{c}\text { Popula } \\
\text { si [5] }\end{array}$ & 1 & 4 & 2 & 3 \\
\hline $\begin{array}{c}\text { Popula } \\
\text { si [7] }\end{array}$ & 2 & 4 & 3 & 1 & X & $\begin{array}{c}\text { Popula } \\
\text { si [6] }\end{array}$ & 2 & 4 & 3 & 1 \\
\hline
\end{tabular}

3. Mutasi. Jumlah populasi yang mengalami mutasi ditentukan oleh parameter mutation rate $(\mathrm{pm})$. Populasi yang akan mengalami mutasi dipilih dengan membangkitkan bilangan random $0-1$, jika nilai random $[\mathrm{k}]<\mathrm{pm}$ maka, populasi tersebut terpilih untuk dimutasi. Selain itu, harus ditentukan juga titik-titik yang akan mengalami mutasi (2 (dua) titik mutasi) dengan cara 
membangkitkan bilangan random dari 1 (satu) sampai panjang kromosom atau pada kasus ini dari $1-4$. Untuk hasil mutasi dapat dilihat pada Tabel 6 .

Tabel 6 Hasil Mutasi

\begin{tabular}{|c|c|c|c|c|c|c|c|c|c|c|}
\hline $\begin{array}{c}\text { Populasi } \\
\text { Mutasi }\end{array}$ & \multicolumn{4}{|c|}{ Kromosom } & \multicolumn{3}{c|}{$\begin{array}{c}\text { Titik } \\
\text { Mutasi }\end{array}$} & \multicolumn{4}{|c|}{ Hasil Mutasi } \\
\hline $\begin{array}{c}\text { Populasi } \\
{[0]}\end{array}$ & 3 & 1 & 2 & 4 & 1 & 4 & 4 & 1 & 2 & 3 \\
\hline $\begin{array}{c}\text { Populasi } \\
{[4]}\end{array}$ & 4 & 3 & 1 & 2 & 4 & 3 & 4 & 3 & 2 & 1 \\
\hline
\end{tabular}

Setelah diperoleh hasil mutasi maka dilakukan proses update generasi dengan mengubah generasi yang lama sesuai dengan hasil mutasi untuk generasi yang baru (populasi akhir). Hasil populasi akhir dapat dilihat pada Tabel.7.

Tabel 7 Tabel Hasil Populasi Akhir

\begin{tabular}{|c|c|c|c|c|c|}
\hline Populasi Ke & \multicolumn{4}{|c|}{ Kromosom } & Fitness \\
\hline Pop ke-0 & 4 & 1 & 2 & 3 & 156,25 \\
\hline Pop ke-1 & 2 & 4 & 3 & 1 & 137,5 \\
\hline Pop ke-2 & 4 & 3 & 1 & 2 & 156,75 \\
\hline Pop ke-3 & 4 & 3 & 1 & 2 & 156,75 \\
\hline Pop ke-4 & 4 & 3 & 2 & 1 & 148,75 \\
\hline Pop ke-5 & 1 & 4 & 2 & 3 & 157,25 \\
\hline Pop ke-6 & 2 & 4 & 3 & 1 & 137,5 \\
\hline Pop ke-7 & 2 & 4 & 3 & 1 & 137,5 \\
\hline Pop ke-8 & 4 & 3 & 2 & 1 & 148,75 \\
\hline Pop ke-9 & 4 & 3 & 2 & 1 & 148,75 \\
\hline
\end{tabular}

\section{Hasil Dan Pembahasan}

Dari perhitungan di atas dapat dibuat Set Parameter AG, yaitu untuk menentukan parameter dari algoritma genetika, yang menggunakan ukuran populasi, maksimum generasi, probabilitas crossover dan probabilitas mutasi sebagai parameternya. Set Parameter AG dapat dilihat pada Gambar 3.

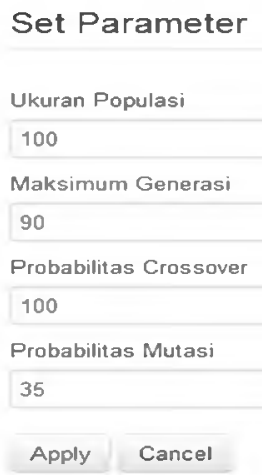

Gambar 3 Set Parameter AG
Set Bobot AG merupakan halaman yang digunakan untuk menentukan bobot dari algoritma genetika yang berfungsi untuk mengatur nilai bobot yang baru. Gambar Set Bobot AG dapat dilihat pada Gambar 4 yaitu:

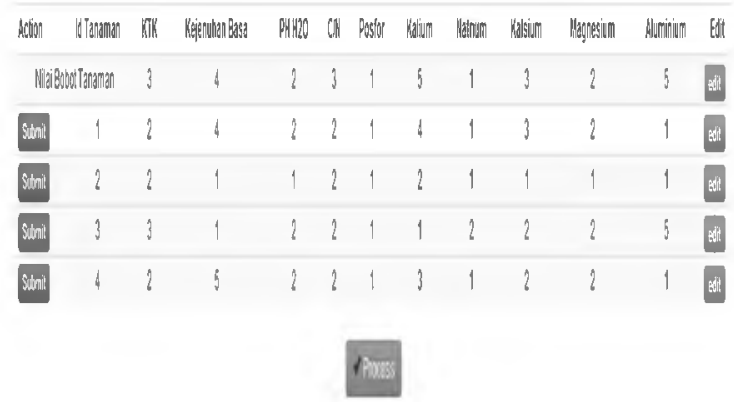

Gambar 4 Set Bobot AG

\subsection{Hasil Algoritma Genetika}

Dari hasil perhitungan Algoritma Genetika yang menampilkan perhitungan algoritma genetika secara detail, yaitu : representasi kromosom, seleksi, crossover, mutasi dan perangkingan. Gambar Hasil Perhitungan Algoritma Genetika dapat dilihat pada Gambar 5 sebagai berikut : 


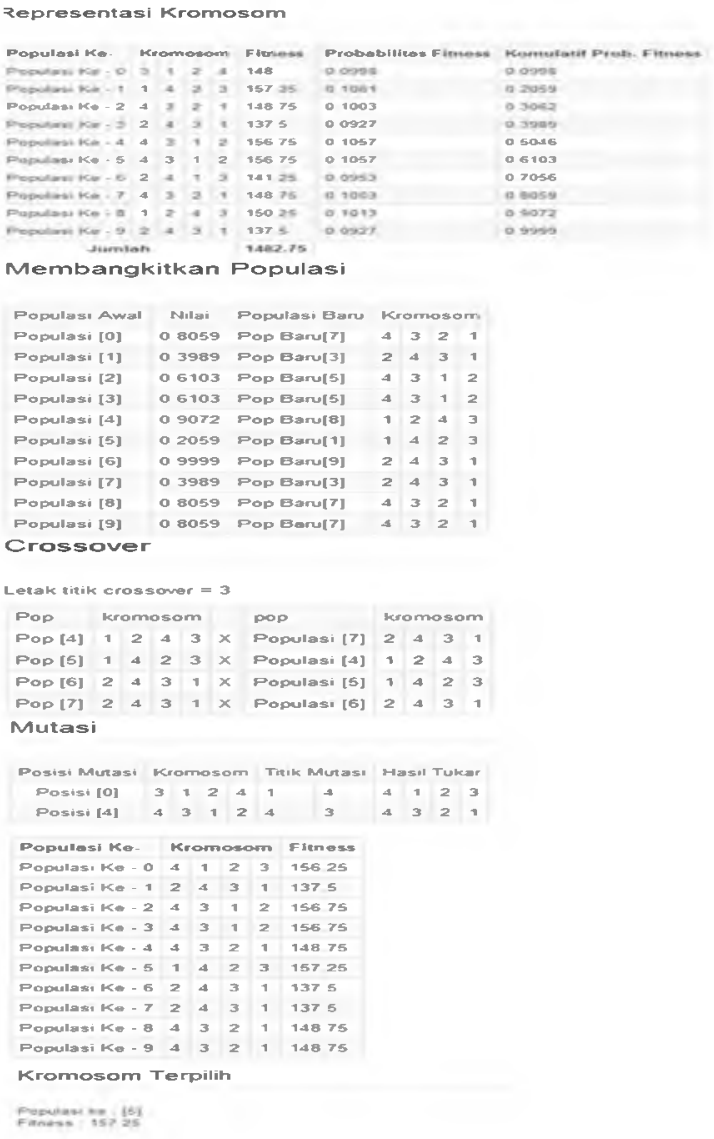

Gambar 5 Halaman Hasil Perhitungan AG

Berdasarkan populasi akhir setelah dilakukan proses update generasi maka diperoleh populasi terbaik, yaitu kromosom terbaik [ $\left.\begin{array}{llll}1 & 4 & 2 & 3\end{array}\right]$ pada populasi generasi ke -5 dengan nilai fitness terbesar $(157,25)$. Dengan begitu, dapat disimpulkan bahwa tanaman yang cocok dan sesuai dengan zat kimia lahan di Kabupaten Bantul yaitu bawang merah kemudian dilanjut umbi garut, ubi jalar dan umbi talas.

Sesuai dengan hasil perangkingan berdasar kromosom terbaik [ $\left.\begin{array}{llll}1 & 4 & 2 & 3\end{array}\right]$, maka dapat digambarkan dalam bentuk grafik perangkingan algoritma genetik sebagai nilai akhir sebagai berikut:

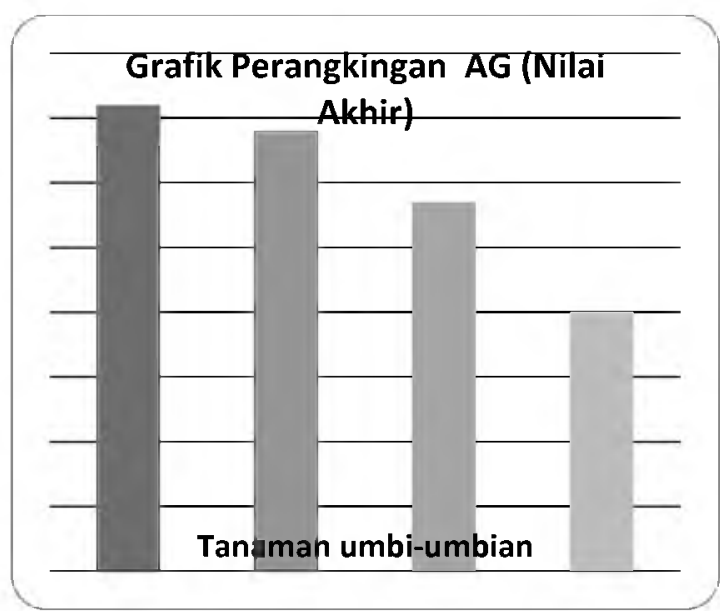

Gambar 6 Grafik Perangkingan AG

5. Kesimpulan

1. Sistem dapat menentukan jenis tanaman yang cocok berdasarkan kandungan zat kimia lahan di wilayah Kabupaten Bantul.

2. Jenis tanaman yang diseleksi dari sistem berdasarkan perangkingan, sehingga diharapkan tanaman bawang merah menjadi unggulan di Kabupaten Bantul.

3. Berdasarkan hasil pengujian dengan Algoritma Genetika diperoleh hasil dengan nilai fitness 157,25, Algoritma Genetika memiliki kelemahan yang selalu berhubungan dengan bilangan random sehingga hasilnya bersifat probabilistik.

\section{SARAN}

Saran yang dapat diberikan untuk perbaikan dan pengembangan dari sistem ini adalah

1. Sistem dilakukan juga untuk pengujian tanaman-tanaman yang lain

2. Menambah kriteria tanaman (unsur hara) agar hasil yang diberikan sistem lebih optimal

3. Membuat tampilan yang lebih rapi dan sederhana (user friendly) agar lebih mudah digunakan oleh user. 
7. Ucapan Terima Kasih

Ucapan terima kasih dihaturkan kepada

Institusi Sekolah Tinggi Teknologi Adisutjipto yang sudah mendanai Penelitian ini.

\section{DAFTAR PUSTAKA}

[1] Ariatin, dkk, 2002, Bibliografi Khusus Tanaman Umbi-umbian"Pusat Perpustakaan Dan Penyebaran Teknologi Pertanian . Bogor.

[2] Benyamin, L.S., 2005, Pemrograman Berorientasi Objek dengan Java, Gava Media. Yogyakarta.

[3] Hardianti Yuyun, dkk, Penerapan Algoritma Genetika dalam Penyelesaian Travelling Salesman" Problem With Precedence Constraints (TSPPC), Jurnal - Online - um.ac.id

[4] Kusumadewi, Sri., Hartati, S., Harjoko, A., dan Wardoyo, R., 2006, Fuzzy Multi-Attribute Decision Making (FUZZY MADM), Graha Ilmu, Yogyakarta.
[5] Jogiyanto, HM., 2005, Analisis dan Desain Sistem Informasi: Pendekatan Terstruktur Teori Dan Praktik Aplikasi Bisnis, Andi offset, Yogyakarta.

[6] Sofwan Aghus, dkk, 2008, "Algoritma Genetika Dalam Pemilihan Spesifikasi Komputer", Proseding Seminar Nasional SNATI 21 Juni 2008, UNDIP, Semarang

[7] Sumartini Dana, Purnomo Budi Santoso dan D. J. Djoko H. S. 2012. "Sistem Pendukung Keputusan Pengobatan Penderita Diabetes Menggunakan Integrasi Decision Table Dan Algoritma Genetika". Jurnal EECCIS Vol.6, No.1. 